\title{
Retraction Note to: Relationships between PON1 Q192R polymorphism and clinical outcome of antiplatelet treatment after percutaneous coronary intervention: a meta-analysis
}

Ping $\mathrm{Li}^{1} \cdot$ Shu-Hong Bu${ }^{1} \cdot$ Xiao-Tong $\mathrm{Lu}^{1} \cdot \mathrm{Li}-\mathrm{Xia} \mathrm{Li}^{1}$ • A-Jing $\mathrm{Xu}^{1} \cdot$ Yue-Nian Tang ${ }^{1} \cdot$ Jian Zhang ${ }^{1}$

Published online: 18 August 2015

(C) Springer Science+Business Media Dordrecht 2015

Retraction Note to: Mol Biol Rep (2014) 41:6263-6273

DOI 10.1007/s11033-014-3509-7

The Publisher and Editor retract this article in accordance with the recommendations of the Committee on Publica tion Ethics (COPE). After a thorough investigation we have strong reason to believe that the peer review process was compromised.

The online version of the original article can be found under doi:10.1007/s11033-014-3509-7.

Jian Zhang

zhangjianzj116@126.com

1 Department of Pharmacy, The Affiliated Xinhua Hospital of Shanghai Jiaotong University, Kongjiang Road No. 1665,

Yangpu District, Shanghai 200082, People's Republic China 